This is the peer reviewed version of the following article: Minkkinen $J$, Lindfors P, Kinnunen J, Finell E, Vainikainen M-P, Karvonen S, Rimpelä, A. Health as a Predictor of Students' Academic Achievement: A 3-Level Longitudinal Study of Finnish Adolescents. J Sch Health. 2017; 87: 902-910. , which has been published in final form at http://dx.doi.org/10.1111/josh.12572. This article may be used for non-commercial purposes in accordance with Wiley Terms and Conditions for Self-Archiving.

Health as a Predictor of Students' Academic Achievement: A Three-level Longitudinal Study of Finnish Adolescents

\title{
Preprint: Health as a Predictor of Students' Academic Achievement: A 3-Level \\ Longitudinal Study of Finnish Adolescents
}

Citation: Minkkinen J, Lindfors P, Kinnunen J, Finell E, Vainikainen M-P, Karvonen S,

Rimpelä, A. Health as a Predictor of Students' Academic Achievement: A 3-Level

Longitudinal Study of Finnish Adolescents. J Sch Health. 2017; 87: 902-910. 


\section{ABSTRACT}

BACKGROUND: Studies have shown a relationship between students' health and their academic achievements, but whether health of classmates and schoolmates impacts individual students' school achievement is less known. We studied these effects on students in lower secondary school in Finland.

METHODS: Students (seventh grade, age 12-13 years., N=7779, 123 schools, 565 classes) participated in a classroom survey measuring health (externalizing and internalizing problems, daily health complaints, and long-term illness) and academic achievement. Academic achievement when leaving school (15-16 years) was obtained from the Finnish national application register on upper secondary education. Three-level (student, class, and school) multilevel regression analyses were executed.

RESULTS: All health variables predicted academic achievement at leaving school at the student level and externalizing and internalizing problems at the class level; better health predicted better achievement. Students' health at the school level was not related to academic achievement. The effect of class-level health on academic achievement was as strong as the effect of student-level health.

CONCLUSION: Both student and classmates' health at the beginning of lower secondary school contribute to academic achievement when leaving school. Keywords: adolescent; school health; externalizing and internalizing behavior; chronic disease; multilevel modeling. 
Health, understood as a total of physical, mental, and social well-being, is an important factor for academic achievement at school. ${ }^{1-5}$ Previous research has shown that good health predicts early academic achievement independently of family risk factors and decreases the likelihood of failing in secondary school. ${ }^{6,7}$ Most studies of health-related determinants of academic achievement have focused upon student characteristics. Less attention has been paid to health factors of the class and school communities where students work, although there is considerable evidence showing that class and school level factors, eg school climate, have impact on students' academic achievement. ${ }^{8-10}$ This study extends previous knowledge about the significance of school communities on students' academic achievement by examining effects of class and school level health: externalizing and internalizing behavior problems, health complaints, and chronic illnesses.

The distinction of children's behavior problems to externalizing (conduct problems, hyperactivity, aggression, irritability, delinquency) and internalizing (sadness, withdrawal, anxiety) expressions is largely used in the literature. ${ }^{11,12}$ Our review is based on the longitudinal studies in externalizing and internalizing behavior problems and academic achievement as no multilevel research was found on the issue. Externalizing problem behavior is associated with poor academic achievement, underachievement, and a higher risk of school failure ${ }^{13-17}$, whereas, the effect of internalizing problems on academic achievement is less clear. ${ }^{14,17}$ In some studies, internalizing problems have predicted boys' higher academic achievement, ${ }^{18}$ whereas in other studies internalizing problems, especially depression, have predicted worse academic achievement in both genders. ${ }^{15,16,19-21}$ Furthermore, reciprocal long-term associations between internalizing problems and school achievement have been detected. ${ }^{22}$ To conclude, the impact of students' externalizing problems behavior on their academic achievement is far more decisive than the effect of internalizing problems. 
Self-perceived health complaints cover symptoms reported by the adolescent him/herself. The symptoms include somatic complaints like musculo-skeletal or stomach pain and psychological symptoms such as having sleeping difficulties. ${ }^{23}$ To our knowledge, there are no prior multilevel studies on the effect of health complaints on academic achievement. Cross-sectional studies have shown that somatic complaints, such as headache and abdominal pain, are related to students' abilities to concentrate and school absenteeism. ${ }^{24,25}$ Also, sleeping difficulties are associated with poor learning and academic achievement. ${ }^{26,27}$

Students' chronic illnesses, such as diabetes and asthma, or disabilities may be a risk for adverse effects on academic achievement through absenteeism and concentration problems. ${ }^{1,28}$ No multilevel research was found, but studies on student level have shown that chronic epilepsy and pediatric traumatic brain injury could have long-term impacts on academic achievement through lower levels of cognitive functioning. ${ }^{29,30}$ Having type 1 diabetes is related to impaired academic achievement due to difficulties in glucose control. ${ }^{31-}$ ${ }^{33}$ Having asthma correlates with children's school attendance, although only slight or no effects have been found on school achievement. ${ }^{34,35}$ However, poorly controlled asthma affects adversely academic achievement through absenteeism and lower cognitive competence. $^{28}$

The objective of this study is to analyze whether students' health at the beginning of lower secondary school, the seventh grade, affects their academic achievement when leaving school at the end of ninth grade. We measure the effects of health at student-, class-, and school-levels as the impact of schoolmates on students' academic achievements is still unclear in health issues. The conceptual model of the study is presented in Figure 1. Further, we compare the effects of class and school means with the corresponding student-level effects to clarify the role of environment. The data comes from Finland where secondary school children have consistently performed well in international educational comparisons, 
eg in Programme for International Student Assessment (OECD 2013) ${ }^{36}$ In Finland, students are divided to classes at the beginning of lower secondary school and the classes are kept the same through the lower secondary school.

\section{METHODS}

\section{Participants}

Participants (12-13 years old) were recruited across comprehensive schools in the Helsinki Metropolitan area in Southern Finland in 2011. A total of 9497 students out of the 13,012 seventh-graders participated in the survey (response rate 73\%), and 8,583 of these had information on their academic achievement in the school leaving certificates available in the national register of the joint application system on students' upper secondary education in 2014. Five schools in the city of Helsinki were omitted (330 students; $2.5 \%$ ) for the reason of refusal ( 2 schools), construction in computer classes ( 2 schools), and delay of the individual passwords for the survey (1 school). The other reasons for the nonresponses were students' absences from the class on the survey day (school absence, student in special needs education; about $10-15 \%$ of the students), and the lack of parents' consent statements. Almost empty and unreliable questionnaires $(\mathrm{N}=42$; profanities in open-ended answers or extreme choices in most answers) were excluded, likewise questionnaires with missing information for class specification.

All the respondents who completed the main variables in the seventh-grade questionnaire and whose school leaving certificates were available in the register were included into analyses. Classes and schools with less than 5 participants were excluded in order to eliminate possible bias for aggregated class- and school-level variables. The final study population included 7,779 students (51.7\% girls), from 565 classrooms and 123 schools. The number of students from each class varied between 5 and 26 students $(M=$ 
15.09, $\mathrm{Sd}=3.95)$ and from each school between 11 and 166 students $(\mathrm{M}=80.58, \mathrm{Sd}=$ $32.43)$.

\section{Non-response analysis}

Students in the final sample were compared to those 9,497 students who completed the questionnaire in the seventh grade using Chi-square statistics or Mann-Whitney U-test, as appropriate. No significant difference was found in gender distribution, parents' education, externalizing and internalizing problem behaviors, daily health complaints, and perceived harms of long-term illness to everyday life. Students in the final sample had higher seventh grade academic achievement $(\mathrm{M}=8.30, \mathrm{Sd}=.87)$ than the whole sample of students, who completed the questionnaire at that time $(\mathrm{M}=8.22, \mathrm{Sd}=.91$; Mann-Whitney U-test, $\mathrm{p}<$ .001). This difference is due to the fact that the national register of the joint application system entails only the grades of those students who applied into general upper secondary or vocational upper secondary education. The register lacks the grades of those students who applied into specialized vocational education and training institutions, to the $10^{\text {th }}$ grade in lower secondary education, to pre-vocational education, or did not apply. The $10^{\text {th }}$ grade in lower secondary education is for those students who want to raise their grades in the school leaving certificate. Prevocational studies are a preventive measure outside the formal education system for young people without employment or a place at the upper secondary level.

\section{Instruments}

The dependent variable, academic achievement in the school leaving certificate from the national register of the joint application system, was studied using a mean of the sum of the grades in three subjects: mother tongue, mathematics, and foreign language (starting in grades $1-3)$. The scale is $4-10(4=$ fail, $10=$ excellent; Table 1$)$. Academic achievement at the seventh grade, which was one of the background variables, was measured similarly. 
Students' externalizing and internalizing problem behaviors in the seventh grade were measured by a Strengths and Difficulties Questionnaire (SDQ) ${ }^{37}$, which is a widely used indicator of psychosocial adjustment among children and adolescents. The SDQ covers conduct problems, emotional symptoms, hyperactivity and inattention, peer relationship problems, and prosocial behaviors and its reliability and validity have been shown to be high. ${ }^{38}$ As it has been recommended to be useful in samples of general population such in this study, we unified the conduct problems and hyperactivity into an externalizing problems scale (10 items) and the emotional symptoms and peer relationship problems into an internalizing problems scale (10 items). ${ }^{39}$ For each item the options included a three-point scale $(0=$ not true, $1=$ somewhat true, $2=$ certainly true $)$. Item ratings were added together to obtain a total score with lower scores indicating fewer problems (scale 0-20; Table 1). Reliability was adequate (externalizing problems: $\alpha=.77$; internalizing problems: $\alpha=.72$ ).

Daily health complaints in the seventh grade were based on ten complaints containing headache, neck and shoulder pain, low back pain, abdominal pain, tension or nervousness, irritation or outbursts of anger, trouble falling asleep or waking at night, feeling tired or weak, feeling dizzy, and trembling of hands. The question was: "In the last 6 months, have you had any of the following health complaints and how often?" Response scale was "rarely or not at all," "approximately once a month," "approximately once a week," and "nearly every day". 23 The last option was coded as 1 , other options as $0 .{ }^{40}$ Item ratings were added to a sum variable (scale 0-10; Table 1).

Self-perceived harm of long-term illness in the seventh grade was composed of two questions: whether participants had a long-term illness or injury (no/yes) and whether they assessed harm of it. "No long-term illness or injury" was coded as 0 in the composite variable. If the student had a long-term illness or injury, the harm of it was gauged with a supplementary question containing four items: "If you have a long-term illness or injury, does 
it harm your every-day life in following areas: home/family, friends, school work, hobbies?" $(0=$ no, $1=$ not very much, $2=$ quite a lot, $3=$ very much $)$. The reliability of these four items was good $(\alpha=0.841)$. Item scores were summed to a total score which ranged from 0 to 12 and this score was added with the question of whether participants had a long-term illness or injury (no $=0$; Table 1$)$. Thus, 0 indicates no long-term illness or injury or no harm of it in the composite variable.

The background variables were academic achievement in the seventh grade, gender (boy $=0$, girl $=1$ ), and parents' education, all reported by students. Previous research has detected excellent validity of the self-reported grades in Finland. ${ }^{41}$ Parents' education was asked separately for mothers and fathers and the highest level of either parents' education was included into analysis. The question was "What kind of education do your parents have?" The options were: basic education only, vocational upper secondary education or vocational college, matriculation examination certificate and vocational college, university degree, no mother/father. University degree was encoded as 1 , other options 0 . No mother and father was coded as a missing value. A total of 37.7 percent of students had at least one parent with university-level education reflecting a high education level in the population of the Helsinki Metropolitan area.

The class- and school-level independent variables were class- and school-level means of the student-level scores.

\section{Procedure}

The survey was executed during the autumn semester of 2011 after obtaining the consent of the educational authorities in the 14 municipalities and the permission of The Ethical Committee of the National Institute of Health and Welfare for the study protocol. An approval from the parents was not obliged as the study was executed as a part of normal school work, but parental consent statements were compiled in two municipalities where they 
were claimed by the local authorities. In the other 12 municipalities information letters were sent to parents. All seventh graders were invited to participate in the study. The survey was completed online in computer classrooms during a normal school day. The participants used personal user names and passwords created by the researchers and delivered by the supervising teachers. The questionnaire consisted of questions regarding wellbeing, health, health behavior, school work, and family background.

\section{Data Analysis}

Multilevel modelling was applied (figure 1) as the method allowed to examine student-, class-, and school-level effects simultaneously by way of splitting the variance of the observed variables to the variance components for each level. ${ }^{42}$ Linear three-level analyses were conducted using the Mplus statistical package (version 7.4). ${ }^{43}$ Maximum likelihood estimation with non-normality robust standard errors was applied (MLR estimator). ${ }^{43}$ Two-tailed significance testing at the criterion level of $p=.05$ was used for the hypothesized associations. Intra-class correlation of each predictor were calculated by using class and school as clustering variables in order to ascertain the percentage of the total variance at each level. ${ }^{42}$ If the variance component of student-level variables was statistically significant at the cluster levels (class, school), a corresponding cluster variable was included into the multilevel analyses taking an aggregated variable (the intraclass correlations; Table 2).

At first, a null model of students nested in classes and schools without any predictors was executed to determine intra-class correlations and between-class and between-school variances in the dependent variable (Model 1). Secondly, health variables were simultaneously included into the random intercept model at the student-, class-, and schoollevel (Model 2). Thirdly, the background variables were added into analysis (Model 3) and 
the effects of student-level variables were compared with the effects of corresponding classand school-level variables using standardized coefficients and z-scores. ${ }^{43,44}$

The predictors were centered according to the established practice in multilevel modelling and the centering method was decided according to the research question. ${ }^{45} \mathrm{We}$ utilized group-mean centering by class for the student-level predictors, group-mean centering by school for the class level predictors and grand-mean centering for the school-level predictors as is recommended for research questions where the effects of the student-level predictors and the corresponding class- and school-level predictors are compared. ${ }^{45,46}$

\section{RESULTS}

Students' academic achievement at leaving school varied significantly across the classes and schools. Intra-class correlation was .81 in the class level and .73 in the school level indicating that $8.1 \%$ of the variation occurred across classes and $7.3 \%$ across schools (Table 2). Moreover, the variations of students' externalizing and internalizing problems and daily health complaints were significant across the classes and schools. On the other hand, self-perceived harm of long-term illness to everyday life did not significantly vary across the classes and schools and it was only used as a student level variable in the analyses (Table 2).

Results of linear multilevel modeling for academic achievement in the school leaving certificate are displayed in Table 3. The strongest health contributor of academic achievement was externalizing problems (Model 2). Externalizing problems predicted lower achievement at the student and class levels but not at the school level after controlling for academic achievement in the seventh grade, gender, and parents' education (Model 3). The class effect of externalizing problems on students' academic achievement (standardized beta $(\beta)=-.108$, $\mathrm{p}<.01)$ did not differ comparing the effect of student-level externalizing problems on his/her academic achievement $(\beta=-.124, \mathrm{p}<.001 ; \mathrm{z}=.440, \mathrm{p}=\mathrm{n} . \mathrm{s})$. 
The seventh grade internalizing problems at the student and class levels were positively related to academic achievement (Model 3). The class effect of internalizing problems $(\beta=.123, \mathrm{p}<.001)$ predicted stronger student academic achievement than studentlevel internalizing problems $(\beta=.069, \mathrm{p}<.001 ; \mathrm{z}=1.611, \mathrm{p}<.05)$.

Daily health complaints and self-perceived harm of long-term illness or injury predicted lower levels of academic achievement at the student level (Model 3). Daily health complaints did not predict academic achievement at the class and school levels. Selfperceived harm of long-term illness or injury was analyzed at the student level only because there was no statistical variance at the class and school levels.

Higher levels of academic achievement in the seventh grade predicted higher academic achievement in the school leaving certificate at the student-, class-, and schoollevels (Model 3; respectively, $\beta=.632, \beta=.767, \beta=.608$; all $p<.001$ ). Seventh grade classlevel academic achievement was a stronger predictor of academic achievement than studentlevel achievement at the seventh grade $(\mathrm{z}=4.301, \mathrm{p}<.001)$.

Girls had higher academic achievement than boys at leaving school and academic achievement was higher in classes with more girls (Model 3). The class-level effect of gender was stronger on academic achievement than the student-level effect (student-level $\beta=.293$, class-level $\beta=.843 ; \mathrm{z}=2.351, \mathrm{p}<.05)$. Gender did not significantly vary across the schools, therefore it was analyzed at the student and class levels only (Table 2).

Parents' higher education predicted student's academic achievement at the student-, class- and school-levels (Model 3; respectively, $\beta=.172, \beta=.798, \beta=2.219$ ). School-effect of parents' education was stronger than student-effect $(\mathrm{z}=4.606, \mathrm{p}<.001)$ and class-effect of parents' education $(\mathrm{z}=2.666, \mathrm{p}<.001)$. Class-level effect of parents' education was stronger than student-level effect $(\mathrm{z}=2.117, \mathrm{p}<.001)$. 
The coefficient of determination $\left(\mathrm{R}^{2}\right)$ in Model 3 was $51.9 \%$ at the student level, $78.6 \%$ at the class level, and $84.5 \%$ at the school level.

\section{DISCUSSION}

This study aimed to assess the importance of health in the school community on student academic achievement. The results showed that not only did student health contribute to subsequent academic achievement but that students' subsequent achievement was influenced by health in the school community as well. The current study makes a contribution to the previous knowledge concerning a substantial effect of classroom health on academic achievement, which is a subject still scarcely studied. Our study also showed that health effects of a class tend to be larger than health effects of a school. ${ }^{9}$

In the current study, both classmates' externalizing and internalizing problems predicted students' later academic achievement while students' health at the school level had no effect. Prior studies pointed out the smaller between-school differences in students' achievement in Finland compared to other countries, which may be due to relatively low socio-economic segregation of residential areas, a common national curriculum, and because a majority of Finnish children choose a local secondary school. ${ }^{18}$

Earlier longitudinal studies have noted that student's externalizing problems predict his/her worse academic achievement. ${ }^{13-17}$ Our study confirmed these findings and we also found that students' externalizing problems in class had relevance, which has not previously been described. Our longitudinal results indicated that later academic achievement was higher in classes where students had less externalizing problems, and externalizing problems in class hinder academic achievement as significantly as students' personal externalizing problems. These findings can be explained by Hinshaw's suggestion that externalizing problem behaviors cause disturbances in the classroom that led to poorer achievement. ${ }^{12}$ 
Moreover, our study produced novel results showing that students' later academic achievement was higher in classes where students had more internalizing problems. A possible explanation might be that concentration could be higher in classrooms where students have a heightened level of internalizing distress, as moderate levels of internalizing problems are associated with more adaptive regulation. ${ }^{47}$ Some studies have also shown that anxiety disorders are associated with higher grades. ${ }^{48}$ However, contradictory student-level findings that less internalizing problems could predict higher academic achievement ${ }^{14}$ imply that more research on this topic needs to be undertaken, especially considering class-level effects.

Having multiple daily health complaints is quite a rare phenomenon in adolescents and still fewer suffer from long-term illness and injury that disturbs everyday life. According to the results, neither problem appears to be relevant on the class and school level. However, at the student level these problems should be tackled in school health and welfare services because chronic conditions are risks for students' academic achievement as earlier research has also indicated. ${ }^{1}$

Our results revealed the link between school health and academic achievement which shows that collaborative approach to learning and health is needed in order to support the full potential of each child. Recently, this kind of approach has been addressed in a Whole School, Whole Community, Whole Child Framework (WSCC) which gives the potential for improving both educational and health outcomes through supporting infrastructures and collaborative partnerships in public health and education. ${ }^{49-51}$

\section{Limitations}

The baseline data in this study was self-reported by students. The limitation concerning the national register data was that it did not include school leaving certificates of those students who did not apply for upper secondary education. These students had on 
average lower academic achievement than those included in the analyses. Thus, the results of this study do not contain students with the weakest academic achievement. On the other hand, the non-response analyses did not show other differences between the baseline sample and the study population.

\section{Conclusions}

This research gives support for the link between school community health and academic outcomes. Both the students' own and classmates' health at the beginning of lower secondary school contribute to students' academic achievement when leaving school. Consequently, health in school communities could have important long-term effects on students' possibilities of access to upper secondary education. Our study implies that multilevel studies on school health in different contexts are needed to show how generalizable these results are. Overall, the significance of the different class compositions on academic achievement should be discovered in future.

\section{IMPLICATIONS FOR SCHOOL HEALTH}

Our results showed that a heightened level of students' externalizing problems in class disturbs learning and predicts poorer academic achievement among the students of the class. This shows that health and well-being are related to education and learning, not only on an individual level but also on class level. It also shows that health and well-being should not be separated from education and learning in school practice, educational policies or research.

Some practical implications can follow from our results. As classmates' health seems to affect the academic achievement of students, more attention should be paid to developing a positive social and emotional climate in classrooms. For school administration, this means paying attention to class formation, eg students with externalizing problems not to be congregated into the same classes. Further, resources in the school could be divided, at least partly, on the grounds of class composition. Classes with high externalizing or corresponding 
problems might benefit from having assisting school personnel in the classrooms. This personnel, part-time or fulltime, can support teachers in organizing everyday work in the classroom or can assist individual students in their tasks. As learning and well-being are closely related, each school and teacher should have access to high quality school health and welfare services, which they could consult when problems are encountered in the class or with individual students.

\section{Human Subjects Approval Statement}

The research procedure was approved by The Ethical Committee of the National Institute of Health and Welfare.

\section{ACKNOWLEDGEMENTS}

This research was supported by a grant from the Academy of Finland by the Competitive Research Funding of the Tampere University Hospital (9P063), Tampere, Finland. We thank our collaborators at the Center for Educational Assessment at the University of Helsinki who has an important role in data collection and planning of this longitudinal study.

\section{REFERENCES}

1. Michael SL, Merlo CL, Basch CE, Wentzel KR, Wechsler H. Critical connections: health and academics. $J$ Sch Health. 2015;85:740-758.

2. Lavin AT, Shapiro GR, Weill KS. Creating an agenda for school-based health promotion: a review of 25 selected reports. $J$ Sch Health. 1992;62:212-229.

3. Novello AC, Degraw C, Kleinman D. Healthy children ready to learn: an essential collaboration between health and education. Public Health Rep. 1992;107:3-15.

4. Shaw SR, Gomes P, Polotskaia A, Jankowska AM. The relationship between student health and academic performance: implications for school psychologists. School Psychology International. 2015;36(2):115-134. 
5. World Health Organization. The Status of School Health. WHO, Geneva. 1996. Available at:

http://www.searo.who.int/nepal/mediacentre/1996_the_status_of_school_health.pdf?ua=1 . Accessed February 20, 2017.

6. Spernak SM, Schottenbauer MA, Ramey SL, Ramey CT. Child health and academic achievement among former head start children. Children and Youth Services Review. 2006;28:1251-1261.

7. Needham BL, Crosnoe R, Muller C. Academic failure in secondary school: the interrelated role of health problems and educational context. Social Problems. 2004;51:569586.

8. Coleman JS, Compbell EQ, Hobson CJ, Mcpartland J, Mood AM, Weinfeld FD et al. Equality of Educational Opportunity. Washington DC: Department of Health, Education \& Welfare Office of Education; 1966.

9. Masci C, Ieva F, Agasisti T, Paganoni AM. Does class matter more than school? Evidence from a multilevel statistical analysis on Italian junior secondary school students. Socio-Economic Planning Sciences. 2016;54:47-57.

10. Mohammadpour E. A three-level multilevel analysis of Singaporean eighth-graders science achievement. Learning and Individual Differences. 2013;26:212-220.

11. Achenbach TM, Edelbrock CS. The classification of child psychopathology: a review and analysis of empirical efforts. Psychological Bulletin. 1978;85:1275-1301.

12. Hinshaw SP. Externalizing behavior problems and academic underachievement in childhood and adolescence: causal relationships and underlying mechanisms. Psychological Bulleting. 1992;111:127-155. 
13. Ansary NS, Luthar SS. Distress and academic achievement among adolescents of affluence: a study of externalizing and internalizing problem behaviors and school performance. Dev Psychopathol. 2009;21:319-341.

14. Breslau J, Miller E, Breslau N, Bohnert K, Lucia V, Schweitzer J. The impact of early behavior disturbances on academic achievement in high school. Pediatrics. 2009;123:1472-1476.

15. van Lier PAC, Vitaro F, Barker ED, Brendgen M, Tremblay RE, Boivin M. Peer victimization, poor academic achievement, and the link between childhood internalizing and externalizing problems. Child Dev. 2012;83(5):1775-88.

16. Masten AS, Roisman GI, Long JD, Burt KB, Obradovic J, Riley JR et al. Developmental cascades: linking academic achievement and externalizing and internalizing symptoms over 20 years. Dev Psychol. 2005;41:733-746.

17. McLeod JD, Uemura R, Rohrman S. Adolescent mental health, behavior problems, and academic achievement. J Health Soc Behav. 2012;53(4):482-497.

18. Yang Hansen K, Gustafsson JE, Rosén M. School performance difference and policy variations in Finland, Norway and Sweden. In K Yang Hansen, JE Gustafsson, M Rosén, S Sulkunen, K Nissinen, P Kupari et al. (eds.), Northern Lights on TIMMS and PIRLS 2011. Copenhagen: Nordic Council of Ministers; TemaNord 2014:528:25-48.

19. Maughan, B, Rowe R, Loeber R, Stouthamer-Loeber M. Reading problems and depressed mood. J Abnorm Child Psychol. 2003;31:219-229.

20. Pelkonen M, Marttunen M, Aro H. Risk for depression: a 6-year follow-up of Finnish adolescents. $J$ Affect Disord. 2003;77(1):41-51.

21. Riglin L, Petrides KV, Frederickson N, Rice F. The relationship between emotional problems and subsequent school attainment: A meta-analysis. $J$ Adolesc. 2014;37:335346. 
22. Weidman AC, Augustine AA, Murayama K, Elliot A. Internalizing symptomatology and academic achievement: bi-directional prospective relations in adolescence. $J$ of Research in Personality. 2015;58:106-114.

23. Haugland S, Wold B. Subjective health complaints in adolescence-reliability and validity of survey methods. J Adolesc. 2001;24:611-624.

24. Vila M, Kramer T, Hickey N, Dattani M, Jefferis H, Singh M, et al. Assessment of somatic symptoms in British secondary school children using the Children's Somatization Inventory (CSI). J Pediatr Psychol. 2009;34(9):989-998.

25. Saps M, Seshadri R, Sztainberg M, Schaffer G, Marshall BM, di Lorenzo C. A prospective school-based study of abdominal pain and other common somatic complaints in children. $J$ Pediatr. 2009;154(3):322-326.

26. Curcio G, Ferrara M, De Gennaro L. Sleep loss, learning capacity and academic performance. Sleep Medicine Reviews. 2006;10(5):323-337.

27. Kronholm E, Puusniekka R, Jokela J, Villberg J, Urrila AS, Paunio T, et al. Trends in self-reported sleep problems, tiredness and related school performance among Finnish adolescents from 1984 to 2011. J Sleep Res. 2014;24(1):3-10.

28. Basch CE. Asthma and the achievement gap among urban minority youth. $J$ Sch Health. 2011;81(10):606-613.

29. Taylor HG, Yeates KO, Wade SL, Drotar D, Stancin T, Minich N. A prospective study of short- and long-term outcomes after traumatic brain injury in children: behavior and achievement. Neuropsychology. 2002;16(1):15-27.

30. Reilly C, Neville B.G.R. Academic achievement in children with epilepsy: a review. Epilepsy Res. 2011;97(1-2):112-123. 
31. Kucera M, Sullivan AL. The educational implications of type 1 diabetes mellitus: a review of research and recommendations for school psychological practice. Psychology in the Schools. 2011;48:587-603.

32. Potts TM, Nguyen JL, Ghai K, Li K, Perlmuter L. Perception of difficulty and glucose control: effects on academic performance in youth with type I diabetes. World Journal of Diabetes. 2015;6(3):527-533.

33. Taras H, Potts-Datema W. Chronic health conditions and student performance at school. $J$ Sch Health. 2005;75(7): 255-266.

34. Suhrcke M, de Paz Nieves C. The Impact of Health and Health Behaviours on Educational Outcomes in High-Income Countries: A Review of the Evidence. Copenhagen: WHO Regional Office of Europe; 2011.

35. Ruijsbroek A, Wijga AH, Gehring U, Kerkhof M, Droomers M. School performance: a matter of health or socio-economic background? Findings from the PIAMA Birth Cohort Study. PLoS One. 2015;10(8):e0134780.

36. OECD. PISA 2012 Results:What StudentsKnow and CanDo - Student Performance in Mathematics, Reading and Science, Vol. I (revised edition). PISA, OECD Publishing, Paris; 2014. Available at: http://dx.doi.org/10.1787/9789264201118-en. Accessed February 20, 2017.

37. Goodman R, Meltzer H, Bailey V. The strengths and difficulties questionnaire: a pilot study on the validity of the self-report version. Eur Child Adolesc Psychiatry. 1998;7:125-130.

38. Goodman R. Psychometric Properties of the Strengths and Difficulties Questionnaire. $J$ Am Acad Child Adolesc Psychiatry. 2001;40(11):1337-1345.

39. Goodman A, Lamping DL, Ploubidis GB. When to use broader internalising and externalising subscales instead of the hypothesised five subscales on the Strengths and 
Difficulties Questionnaire (SDQ): Data from British parents, teachers and children. $J$ Abnorm Child Psychol. 2010;38:1179-1191.

40. Koivusilta L, Kuoppamäki H, Rimpelä A. Energy drink consumption, health complaints and late bedtime among young adolescents. Int J Public Health. 2016;61(3):299-306.

41. Kupiainen S. Vainikainen M-P, Marjanen J, Hautamäki J. The role of time on task in computer-based low-stakes assessment of cross-curricular skills. Journal of Educational Psychology. 2014;106(3):627-638.

42. Heck RH, Thomas SL. An Introduction to Multilevel Modeling Techniques. (2 ${ }^{\text {th }}$ edition). New York: Routledge; 2009.

43. Muthén LK, Muthén BO. Mplus User's Guide. ( $7^{\text {th }}$ edition). Los Angeles, CA: Muthén \& Muthén; 1998-2012.

44. Paternoster R, Brame R, Mazerolle P, Piquero A. Using the correct statistical test for equality of regression coefficients. Criminology. 1998;36(4):859-866.

45. Enders CK, Tofighi D. Centering predictor variables in cross-sectional multilevel models: A new look at an old issue. Psychological Methods. 2007;12:121-138.

46. Hox J. Multilevel analysis: Techniques and Applications. New York: Routledge; 2010.

47. Tandon M, Cardeli E, Luby J. Internalizing disorders in early childhood: a review of depressive and anxiety disorders. Child Adolesc Psychiatr Clin N Am. 2009;18(3):593610.

48. Svanum S, Zody ZB. Psychopathology and college grades. Journal of Counseling Psychology. 2001;48(1):72-76.

49. ASCD. Centers for Disease Control and Prevention (CDC). Whole School, Whole Community, Whole Child: A Collaborative Approach to Learning and Health. ASCD: Alexandria, VA; 2014. Available at: 

Study of Finnish Adolescents

http://www.ascd.org/ASCD/pdf/siteASCD/publications/wholechild/wscc-a-collaborativeapproach.pdf. Accessed February 20, 2017.

50. Kolbe LJ, Allensworth DD, Potts-Datema W, White DR. What have we learned from collaborative partnerships to concomitantly improve both education and health? $J$ Sch Health. 2015;85(11):766-774.

51. Murray SD, Hurley J, Ahmed SR. Supporting the whole child through coordinated policies, processes, and practices. $J$ Sch Health. 2015;85(11):795-801. 

Study of Finnish Adolescents

Figure 1. Conceptual Model
7th grade
9th grade

School level
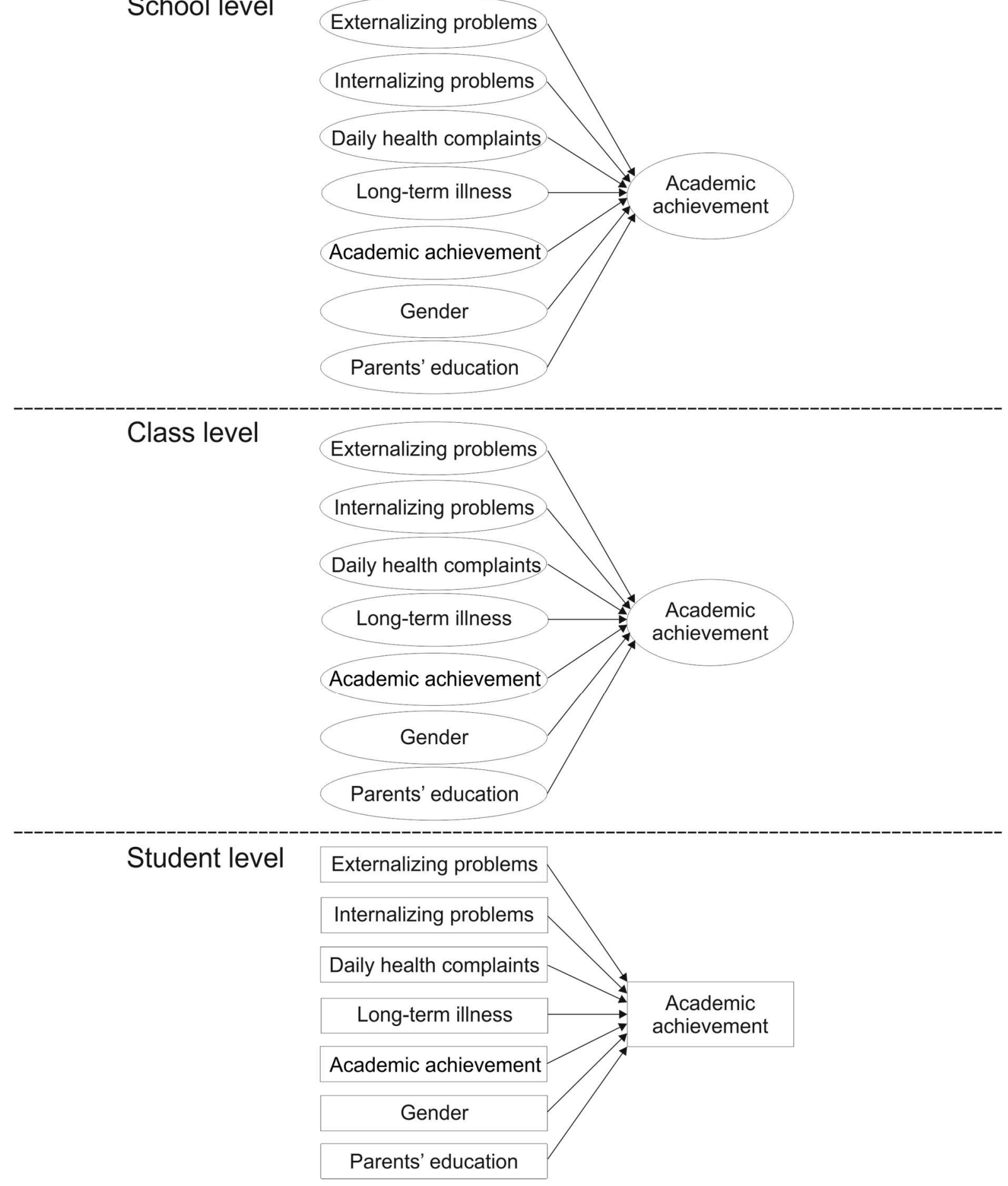


\section{TABLES}

Table 1. Descriptive Statistics of Achievement and Health Variables (N=7779)

Mean SD Skewness Kurtosis Range

\begin{tabular}{lrrrrr}
\hline Academic achievement & & & & & \\
Academic achievement (7th grade) & 8.295 & .869 & -.421 & .083 & $4-10$ \\
Academic achievement (9th grade) ${ }^{1}$ & 8.082 & 1.076 & -.275 & -.624 & $4-10$ \\
Health variables (7th grade) & & & & & \\
Externalizing problems & 4.620 & 3.231 & .903 & .806 & $0-20$ \\
Internalizing problems & 4.472 & 3.121 & .878 & .656 & $0-20$ \\
Daily health complaints & .449 & 1.052 & 3.438 & 15.086 & $0-10$ \\
Harm of long-term illness to everyday life & .643 & 1.732 & 3.409 & 12.758 & $0-12$ \\
\hline
\end{tabular}

Note: ${ }^{1}$ Academic achievement in the school leaving certificate.

Higher scores are indicative of higher levels of variables. 
Table 2. Intraclass Correlations (ICC) and Variance Estimates at the Student, Class and School Levels (Standard Errors in Parentheses) (N Student Level=7779, N Class Level=565, N School Level=123).

\begin{tabular}{|c|c|c|c|c|c|}
\hline Variables & $\begin{array}{l}\mathrm{ICC} \\
\text { Class } \\
(\%)\end{array}$ & $\begin{array}{c}\text { ICC } \\
\text { School } \\
(\%)\end{array}$ & $\begin{array}{l}\text { Within-group } \\
\text { variance, } \\
\text { student level } \\
\text { (SE) }\end{array}$ & $\begin{array}{l}\text { Between-class } \\
\text { variance (SE) }\end{array}$ & $\begin{array}{l}\text { Between-school } \\
\text { variance (SE) }\end{array}$ \\
\hline \multicolumn{6}{|l|}{ Academic achievement } \\
\hline $\begin{array}{l}\text { Academic achievement ( } 7 \text { th } \\
\text { grade) }\end{array}$ & 9.4 & 4.6 & $5.878(.178)^{* * *}$ & $.634(.081)^{* * *}$ & $.294(.075)^{* * *}$ \\
\hline $\begin{array}{l}\text { Academic achievement } \\
(9 \text { th grade })^{1}\end{array}$ & 8.1 & 7.3 & $8.902(.233)^{* * *}$ & $.851(.113)^{* * *}$ & $.765(.187)^{* * *}$ \\
\hline \multicolumn{6}{|l|}{$\begin{array}{l}\text { Health variables in the } 7 \text { th } \\
\text { grade }\end{array}$} \\
\hline Externalizing problems & 3.0 & 2.0 & $9.915(.226)^{* * *}$ & $.311(.075)^{* * *}$ & $.214(.063)^{* *}$ \\
\hline Internalizing problems & 2.5 & 1.1 & $9.396(.199) * * *$ & $.238(.073)^{* *}$ & $.107(.042)^{*}$ \\
\hline Daily health complaints & 1.7 & .6 & $1.083(.060)^{* * *}$ & $.017(.007)^{*}$ & $.007(.003)^{*}$ \\
\hline $\begin{array}{l}\text { Harm of long-term illness } \\
\text { to everyday life }\end{array}$ & 1.3 & .1 & $2.962(.143)^{* * *}$ & $.039(.021)$ & $.001(.007)$ \\
\hline \multicolumn{6}{|l|}{ Background variables } \\
\hline Girl & 2.9 & .3 & $.242(.002)^{* * *}$ & $.007(.002)^{* *}$ & $.001(.001)$ \\
\hline Parents' education & 3.3 & 6.5 & $.213(.003)^{* * *}$ & $.008(.002)^{* * *}$ & $.015(.003)^{* * *}$ \\
\hline
\end{tabular}

Note: ${ }^{1}$ Academic achievement in the school leaving certificate.

$* \mathrm{p}<.05, * * \mathrm{p}<.01, * * * \mathrm{p}<.001$, two-tailed. 
Table 3. Estimates of Hierarchical Linear Modeling for Academic achievement in the School Leaving Certificate $(\mathrm{N}=7779)$

\begin{tabular}{|c|c|c|c|c|c|c|}
\hline \multirow[b]{2}{*}{ Parameters } & \multicolumn{3}{|c|}{ Model 1} & \multicolumn{3}{|c|}{ Model 2} \\
\hline & Estimate $^{1}$ & $S E$ & p-Value & Estimate $^{1}$ & $S E$ & $p$-Value \\
\hline Intercept & 24.245 & 0.097 & .000 & 24.208 & 0.080 & 0.000 \\
\hline \multicolumn{7}{|c|}{ Regression coefficients (fixed effects) } \\
\hline \multicolumn{7}{|c|}{ Student level, 7 th grade } \\
\hline Externalizing problems & & & & -.309 & .013 & .000 \\
\hline Internalizing problems & & & & .147 & .014 & .000 \\
\hline Daily health complaints & & & & -.001 & .038 & .980 \\
\hline $\begin{array}{l}\text { Harm of long-term illness to } \\
\text { everyday life }\end{array}$ & & & & -.120 & .023 & .000 \\
\hline \multicolumn{7}{|l|}{ Academic achievement } \\
\hline \multicolumn{7}{|l|}{ Girl } \\
\hline \multicolumn{7}{|l|}{ Parents' education } \\
\hline \multicolumn{7}{|l|}{ Class level, 7th grade } \\
\hline Externalizing problems ${ }^{2}$ & & & & -.454 & .060 & .000 \\
\hline Internalizing problems ${ }^{2}$ & & & & .268 & .067 & .000 \\
\hline Daily health complaints ${ }^{2}$ & & & & .045 & .225 & .841 \\
\hline \multicolumn{7}{|l|}{$\begin{array}{l}\text { Academic achievement }{ }^{2} \\
\text { Girl }^{2}\end{array}$} \\
\hline \multicolumn{7}{|l|}{ Parents' education ${ }^{2}$} \\
\hline \multicolumn{7}{|l|}{ School level, 7th grade } \\
\hline Externalizing problems ${ }^{3}$ & & & & -.766 & .159 & .000 \\
\hline Internalizing problems ${ }^{3}$ & & & & -.308 & .182 & .090 \\
\hline Daily health complaints ${ }^{3}$ & & & & .775 & .565 & .170 \\
\hline \multicolumn{7}{|l|}{ Academic achievement ${ }^{3}$} \\
\hline \multicolumn{7}{|l|}{$\begin{array}{l}\text { Parents' education }{ }^{3} \\
\text { Variance components (random } \\
\text { effects) }\end{array}$} \\
\hline Student level residual variance & 8.902 & .233 & .000 & 8.002 & .201 & .000 \\
\hline Class level residual variance & .851 & .113 & .000 & .736 & .103 & .000 \\
\hline School level residual variance & .765 & .187 & .000 & .448 & .112 & .000 \\
\hline \multicolumn{7}{|l|}{ Model fit information } \\
\hline Loglikelihood H0 Value & & & 9843.775 & & & -19407.859 \\
\hline Deviance (BIC) & & & 9723.387 & & & 38941.146 \\
\hline
\end{tabular}

Note: ${ }^{1}$ Unstandardized estimates, ${ }^{2}$ class mean, ${ }^{3}$ school mean. 
Table 3. Continuous

Model 3

\begin{tabular}{|c|c|c|c|}
\hline Parameters & Estimate $^{1}$ & $S E$ & p-Value \\
\hline Intercept & 24.181 & .049 & .000 \\
\hline \multicolumn{4}{|c|}{ Regression coefficients (fixed effects) } \\
\hline \multicolumn{4}{|c|}{ Student level, 7th grade } \\
\hline Externalizing problems & -.120 & .009 & .000 \\
\hline Internalizing problems & .068 & .010 & .000 \\
\hline Daily health complaints & -.069 & .029 & .017 \\
\hline \multicolumn{4}{|c|}{ Harm of long-term illness to everyday } \\
\hline life & -.061 & .016 & .000 \\
\hline Academic achievement & .792 & .016 & .000 \\
\hline Girl & .858 & .062 & .000 \\
\hline Parents' education & .502 & .059 & .000 \\
\hline \multicolumn{4}{|l|}{ Class level, 7th grade } \\
\hline Externalizing problems ${ }^{2}$ & -.117 & .037 & .002 \\
\hline Internalizing problems ${ }^{2}$ & .139 & .037 & .000 \\
\hline Daily health complaints ${ }^{2}$ & -.121 & .141 & .389 \\
\hline Academic achievement ${ }^{2}$ & .813 & .033 & .000 \\
\hline Girl $^{2}$ & .854 & .236 & .000 \\
\hline Parents' education ${ }^{2}$ & .808 & .304 & .008 \\
\hline \multicolumn{4}{|l|}{ School level, 7th grade } \\
\hline Externalizing problems ${ }^{3}$ & -.087 & .112 & .442 \\
\hline Internalizing problems ${ }^{3}$ & -.072 & .114 & .529 \\
\hline Daily health complaints ${ }^{3}$ & -.332 & .352 & .346 \\
\hline Academic achievement ${ }^{3}$ & .797 & .084 & .000 \\
\hline Parents' education ${ }^{3}$ & 2.279 & .473 & .000 \\
\hline \multicolumn{4}{|c|}{ Variance components (random effects) } \\
\hline Student level residual variance & 4.111 & .130 & .000 \\
\hline Class level residual variance & .219 & .040 & .000 \\
\hline School level residual variance & .163 & .042 & .000 \\
\hline \multicolumn{4}{|l|}{ Model fit information } \\
\hline Loglikelihood H0 Value & \multicolumn{3}{|c|}{-16740.943} \\
\hline Deviance $(\mathrm{BIC})$ & \multicolumn{3}{|c|}{33678.989} \\
\hline
\end{tabular}

Note: ${ }^{1}$ Unstandardized estimates, ${ }^{2}$ class mean, ${ }^{3}$ school mean. 